\title{
TURISMO EM CURITIBA, PR: UM HISTÓRICO DE SUA INSTITUCIONALIZAÇÃO NO SETOR PÚBLICO
}

\author{
THE INSTITUTIONALIZATION OF TOURISM IN THE PUBLIC SECTOR OF CURITIBA, PR
}

TURISMO EN CURITIBA, PR: UNA HISTORIA DE SU INSTITUCIONALIZACIÓN EN EL SECTOR PÚBLICO

Bruno Martins Augusto Gomes

Professor do Departamento de Turismo e do Programa de Pós-Graduação em Turismo da Universidade Federal do Paraná

Doutor em políticas Públicas pela UFPR gomesbma@ufpr.br

Huáscar Fialho Pessali Professor do Departamento de Economia e dos Programas de Pós-Graduação em Políticas Públicas e em Ciência Política da Universidade Federal do Paraná,

Bolsista Produtividade do CNPq Doutor pela University of Hertfordshire, Inglaterra. pessali@ufpr.br

Data de Submissão: 22/05/2016

Data de Aprovação: 15/03/2017

RESUMO: A atuação do setor público no turismo em Curitiba passa por diferentes momentos desde a década de 1970. Através de entrevistas com agentes do setor público e privado ligados ao turismo na cidade e de análise documental, este artigo delineia a institucionalização do turismo no poder público municipal desde aquele momento até os dias atuais. Sua origem é caracterizada por inter-relações muito fragmentadas, seguida de um período de relativa aglutinação e organização em órgãos variados do poder público municipal. Só em meados dos anos 2000 ele é institucionalizado de forma mais coesa no Instituto Municipal de Turismo. Sua consolidação enfrenta ainda fragilidades como restrita dotação orçamentária, dependência para com o governo federal, e a responsabilidade por ações mais próximas da alçada de outros órgãos municipais.

PALAVRAS-CHAVE: Curitiba. Turismo. Instituições. Políticas Públicas. História.

ABSTRACT: The role of the local public sector in the tourism of Curitiba goes through different periods from the 1970s. Through interviews with local private and public agents related to tourism in the city and document analysis, this article outlines the institutionalization of tourism by the municipal government since that period to the present day. It starts with fragmented interactions between the private and public sector and within the public sector itself, followed by a period of relative agglutination and organization in various departments of the municipal government. Only in the mid-2000s tourism is institutionalized more cohesively in the Municipal Tourism Institute. Its consolidation still faces obstacles such as a small budget, dependence upon the federal government, and being assigned public works that usually fall under another department's responsibility.

KEYWORDS: Curitiba. Tourism. Institutions. Public Policy. History.

RESUMEN: La actuación del sector público en el turismo en Curitiba pasó por diferentes momentos desde la década de 1970. A través de entrevistas con agentes del sector público y privado vinculados al turismo en la ciudad y de un análisis documental, este artigo delinea la institucionalización del turismo en el poder público municipal desde aquel momento hasta la actualidad. Su origen se caracteriza por interrelaciones muy fragmentadas, seguido de un período de relativa aglutinación y organización en diversos órganos del poder público municipal. Solo a mediados de los años 2000 se institucionaliza de forma más unificada en el Instituto Municipal de Turismo. Su consolidación todavía enfrenta fragilidades tales como un presupuesto muy restringido, dependencia del gobierno federal, y la responsabilidad por acciones más cercanas a la jurisdicción de otros órganos municipales.

PALABRAS CLAVE: Curitiba. Turismo. Instituciones. Políticas Públicas. Historia. 


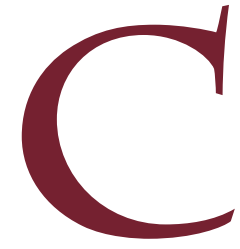

uritiba, capital e município mais populoso do estado do Paraná, segundo estimativa do Instituto Municipal de Turismo (IMT), recebe entre 3,45 milhões e 3,72 milhões de visitantes anuais, número aproximadamente 2,5 vezes maior que o 1,1 milhão de visitantes recebidos em 2000 (KOWALSKI, 2016). Esses números são resultado de décadas de ações em que, em alguma medida, contaram com a coordenação, intermediação ou intervenção direta do setor público municipal através de seus diferentes arranjos institucionais vinculados ao turismo.

Esse fator compele a delinear melhor a trajetória e a evolução desses arranjos, bem como de suas principais contribuições ao turismo local, de modo a institucionalizar as ações e as interações no setor ao longo dos anos. Com o intuito de contribuir para a memória do turismo na cidade de Curitiba, este artigo faz um histórico da institucionalização do turismo no setor público municipal e em suas políticas de turismo desde a década de 1970 até 2015. Como exposto por Bonfim e Bahl (2012), até os anos 60 Curitiba tinha pouca relevância entre as maiores cidades brasileiras, capital de um Estado marcadamente agrícola, e que convivia com problemas urbanos (loteamentos ilegais, trânsito desordenado, inundações, ruas estreitas, edificações malconservadas e favelização).

Em termos metodológicos, para coletar as informações sobre a trajetória das instituições de políticas públicas de turismo em Curitiba, foi realizada uma pesquisa documental utilizando leis do município e notícias oficiais sobre o tema. E também foram entrevistados vinte e seis agentes do setor público e da iniciativa privada ligados ao turismo em Curitiba - em sua maioria ocupantes de cargos de presidência ou direção nas organizações representativas dos empresários ou nos órgãos públicos.

Dessa forma, o artigo está organizado em cinco seções. A primeira aborda aos fundamentos teóricos institucionalistas. Em seguida, são expostos os procedimentos metodológicos. Então expõe-se a origem dispersa da institucionalização do turismo. Em seguida apresenta-se o primeiro período do 
turismo na cidade com esforços de agregação de atores em áreas distintas do turismo. Destaca-se a seguir a criação do Instituto Municipal de Turismo (IMT), um momento importante da institucionalização do turismo no setor público municipal. As considerações finais resgatam a trajetória exposta e apontam para as incertezas que tal institucionalização ainda carrega.

\section{FUNDAMENTOS INSTITUCIONALISTAS}

A teoria institucional, como afirma Ligero (2010), é multidisciplinar e com aplicações em vários ramos da ciência. As suas áreas originárias são a sociologia, a ciência política e a economia, conforme exposto por Théret (2003). A partir dessas, tem-se a sua utilização na compreensão de outras áreas como os estudos das organizações, do turismo e das políticas públicas.

Na sociologia, como afirma Scott (2008), as instituições, tema de estudos de autores como DiMaggio e Powell, Berger e Luckmann, Meyer e Rowan, e Parsons, são compreendidas como um sistema de normas, que se adapta ao ambiente e que regula a relação entre os indivíduos na medida em que estes se confrontam com ele como um fato externo e coercitivo, a seguem não pelo autointeresse, mas por internalizarem-no.

Na Ciência Política, inicialmente a abordagem institucional se dedicava a questões constitucionais, morais, comportamento eleitoral, partidos políticos e opinião pública (SCOTT, 2008). Posteriormente, passou a enfatizar a influência da sociedade no sistema político (grupos de pressão) e o individualismo metodológico (enfoque no indivíduo e sua motivação para a maximização da utilidade), dando origem ao neoinstitucionalismo na ciência política, ou novo institucionalismo, que se distingue em três escolas de pensamento: histórica, sociológica e escolha racional (HALL; TAYLOR, 2003).

Os teóricos da escolha racional consideram que o comportamento é determinado por um cálculo estratégico influenciado pelas expectativas sobre o comportamento dos outros atores (HALL; TAYLOR, 2003). Immergut (1998) relata que os institucionalistas históricos tratam das questões de poder

e interesses com ênfase na influência da história, e das peculiaridades do destino. E a teoria neoinstitucional em sua vertente sociológica, de acordo com Codato e Pereira (2012), compreende a instituição de uma maneira mais 
abrangente que as adotadas nas demais vertentes do neoinstitucionalismo, incluindo regras, procedimentos, sistemas de símbolos, esquemas cognitivos e modelos morais que conferem significado à ação humana e direcionam essa ação.

Na economia, segundo Hamilton (1919), a demanda pelo controle, aliada à percepção de que as atividades econômicas são regidas por convenções e hábitos de pensamento, tornou o institucionalismo relevante. Thorstein Veblen, John Commons e Westley Mitchell, a partir do século XIX, formaram a base dos estudos das instituições na economia. Para estes três autores as instituições consistiam num padrão de comportamento coletivo, parte do universo cultural, o que, portanto, incluía não apenas organizações, mas também costumes, leis, modos de pensamento e ação, sendo importante identificar as suas mudanças (ALMEIDA, 1983). Cabe destacar o entendimento de Commons (1931), o qual traz o conceito de instituições frequente na economia, definindo-as como uma ação coletiva na liberação, no controle e na expansão da ação individual, tendo como unidade básica de análise a transação. O referido autor ressalta que as transações ocorrem em um ambiente de negociação, o qual é marcado por cooperação, barganhas e incertezas.

Pessali e Dalto (2010) acrescentam que, nos estudos sobre desenvolvimento econômico, além dos temas relacionados ao crescimento (acumulação de capital, aumento da força de trabalho, progresso tecnológico, ampliação dos mercados e divisão do trabalho), percebeu-se a necessidade de agregar às explicações outros aspectos como sistemas de inovação, arranjos produtivos, redes de cooperação, reformas institucionais e direitos de propriedade. Neste debate, segundo os referidos autores, a interação dos indivíduos e os padrões regulares de pensamento e ação se tornam relevantes. Assim, "as instituições ganham destaque como engrenagem importante do desenvolvimento ao mesmo tempo em que podem ser vistas como uma de suas medidas" (PESSALI; DALTO, 2010, p. 12).

Doctor (2003) expõe que as instituições importam, pois afetam o desempenho econômico na medida em que moldam expectativas e comportamento de todos os agentes políticos e econômicos nas tomadas de decisão ao longo do 
processo político. Cimoli et al. (2007), por sua vez, afirmam que as políticas e as instituições afetam as capacidades tecnológicas, o ritmo de aprendizado e a interação das organizações entre elas e com o governo.

A partir da segunda metade do século XX, a Nova Economia Institucional, segundo Scott (2008), enfatiza a racionalidade limitada, com enfoque no estudo dos processos, considerando o aprendizado entre os agentes e também a presença das estruturas institucionais, especialmente do governo, na coordenação das atividades econômicas. De acordo com Hodgson (2007a), a nova economia institucional busca explicar a existência de instituições políticas, jurídicas e sociais por meio de um modelo do comportamento individual, traçando as consequências destas instituições nas interações humanas. Immergut (1998) acrescenta que a ênfase no comportamento observável é precisamente o ponto de partida para os novos institucionalistas, mas eles rejeitam o comportamento como referência básica de análise. Como exposto por este autor, eles buscam analisar por que os agentes fazem determinadas escolhas. Dessa forma, nesta pesquisa, ao analisar a interação empresários-setor público no turismo, tem-se como base a teoria institucional, compreendendo instituições como hábitos coletivos de pensamento e ação (HODGSON, 2003).

No turismo a abordagem institucional ainda é reduzida, porém como observado por Alonso et al. (2015), é relevante a importância das instituições nas análises do setor público no turismo.

Ao estudarem o enoturismo, Alonso et al. (2015) identificaram como desafios para o desenvolvimento da atividade exatamente a influência das políticas públicas (principalmente impostos, infraestrutura e maior interação empresáriossetor público), das leis (como a legislação sobre transporte de líquidos em aviões e sobre o nível de álcool consumido por motoristas), além das influências do ambiente externo (sendo eles o terrorismo e a crise econômica).

Rawlence (2010), integrando a economia dos custos de transação a outras teorias institucionais para estudar uma região turística da China, relata presença de oportunismo, racionalidade limitada e incerteza. Gomes (2008) utiliza a economia dos custos de transação para demonstrar que as transações entre os 
agentes dos setores público e privado em regiões turísticas são influenciadas por oportunismo, incertezas, frequência e investimento em ativos específicos.

Grechi (2011) investiga a relação entre o ambiente institucional de destinos turísticos e o desenvolvimento local endógeno a partir de um estudo em Bonito (MS). Massukado (2011), por sua vez, utiliza a teoria institucional para analisar a articulação dos agentes na formação de regiões turísticas. Cintra et al. (2016) se pautam nas teorias do stakeholder e no institucionalismo sociológico para identificarem o ambiente institucional, as organizações que o formam e as respectivas influências entre estas no turismo em Londrina, PR.

Pimentel (2014), em um ensaio teórico sobre a análise de políticas públicas de turismo, destaca a importância da investigação do arranjo institucional do setor e os seus respectivos padrões de interação. Mendonça (2012) acrescenta que a eficácia no turismo depende do potencial físico, da prestação de serviços, do ambiente institucional e da interação entre os agentes.

Assim, ficam evidentes as contribuições do institucionalismo para a compreensão do turismo, visto que, conforme exposto por Ligero (2010), o entorno institucional explica o comportamento institucionalizado em agentes empresariais do turismo.

\section{PROCEDIMENTOS METODOLÓGICOS}

Esta pesquisa busca investigar os detalhes históricos envolvidos na institucionalização do turismo no setor público de Curitiba, para tanto tem um caráter qualitativo. O período analisado compreende os anos de 1970 a 2015, visto que é neste período de tempo que o turismo se institucionaliza no setor público e é sobre ele que há maior disponibilidade de dados.

Foram utilizados para a coleta de dados a pesquisa bibliográfica, principalmente em textos publicados pelo poder executivo municipal. Também se adotou como fonte de dados a realização de vinte e seis entrevistas com agentes dos setores público e privado ligados ao turismo em Curitiba, todos eles atuantes em cargos de direção da organização que atuavam.

A seleção dos entrevistados voltou-se primeiramente para os agentes (setor público e privado) relacionados ao Conselho Municipal de Turismo de Curitiba. 
De forma complementar, seguindo Alencar (2007), adotou-se a amostragem tipo bola de neve, solicitando aos entrevistados que indicassem outras pessoas que julgavam ser relevantes para a compreensão da interação dos empresários com o setor público. Tanto os agentes selecionados pelo pesquisador quanto aqueles indicados pelos entrevistados tinham histórico de atuação vinculada ao turismo municipal. As entrevistas foram realizadas por meio do deslocamento do pesquisador até o local agendado previamente com o entrevistado.

A coleta de dados se pautou em roteiro de entrevista e de análise dos documentos que tratavam dos temas: o histórico da interação empresários de turismo com a prefeitura; os órgãos responsáveis pelo turismo antes da criação do IMT; os problemas enfrentados pelo turismo local nessa época; as ações desempenhadas pelo IMT desde sua criação até a segunda década dos anos 2000; os desafios enfrentados por ele desde sua criação; as contribuições das gestões que governaram Curitiba e o que trouxeram para o turismo.

Após a realização da pesquisa documental e das entrevistas, a análise dos dados seguiu parte das etapas da teoria fundamentada (Grounded Theory) categorização e codificação aberta - Strauss e Corbin (2008), Bryant e Charmaz (2010) e Tarozzi (2011). Primeiramente os dados levantados foram transcritos. Em seguida foi elaborada uma lista com principais temas comuns aos mesmos, atribuindo um código a cada um. Então os dados foram identificados conforme sua relação com a lista de códigos. Essa etapa, seguindo as proposições de Strauss e Corbin (2008), denomina-se conceituação, ou seja, uma nomeação dos fenômenos presentes nos dados coletados.

Após a identificação do conteúdo das entrevistas e dos documentos, estes foram inseridos em arquivos de textos referentes a cada tema específico. Após realizar esta separação, o conteúdo de cada categoria foi ampliado por meio de memorandos - frases ou parágrafos analisando o conteúdo das normas. Para a realização da análise dos dados utilizou-se o apoio do software Atlas Ti.

\section{ORIGENS DA INSTITUCIONALIZAÇÃO PÚBLICA DO TURISMO EM CURITIBA: DISTRAÍDOS VENCEREMOS}

A trajetória da institucionalização do turismo no setor público de Curitiba remete pelo menos à década de 1960. A partir de esforços iniciais de interação 
entre o setor público e o setor privado, apresentando suas demandas na área, é que a municipalidade começou a incorporar o turismo em sua organização (MOURA, 2007). Como resultado, no início dos anos 1970 a estruturação do turismo na cidade foi colocada sob a responsabilidade de uma divisão do Departamento de Relações Públicas e Promoções, que comportava também a assessoria de imprensa e a área cultural (ZARUCH, 2014). Ao longo das décadas seguintes, a atuação do setor público no turismo passou por diversas mudanças tanto em sua organização quanto em sua orientação.

Na década de 1980, na gestão do prefeito Maurício Fruet, foi criada em Curitiba a Secretaria de Turismo. Sua principal responsabilidade era organizar o carnaval da cidade e cuidar das manifestações do artesanato local. De acordo com Zaruch (2014, p. 1) ao se referir a essa época, "nunca se preocupou com a promoção da cidade com a finalidade de atrair turistas e eventos".

No final da década de 1980 e início da década de 1990, durante o terceiro mandado do prefeito Jaimer Lerner, o turismo passou a ser responsabilidade da Fundação Cultural de Curitiba (FCC), que havia sido criada em 1973 durante seu primeiro mandato. A FCC foi responsável pela criação da Feira de Artesanato do Largo da Ordem. A feira tem sua história vinculada às feiras que aconteciam nas praças Zacarias e Rui Barbosa e foi parte de um projeto do referido prefeito para revitalizar o centro histórico da cidade. O entrevistado A13 (setor público), por exemplo, relatou:

O centro histórico era uma área mal frequentada o que impedia as famílias de circularem por lá. Era mal iluminado, feio, escuro. Ele foi revitalizado e incentivou-se a ida de restaurantes e galerias de arte e a Feira teve muita importância. (ENTREVISTADO A13 SETOR PÚBLICO).

Mas o turismoera uma atividadeum tanto distante dasprincipais preocupações e responsabilidades daquele órgão. De acordo com o entrevistado J18 (setor privado), nessa época "o turismo era um elemento estranho na FCC, não tinha condições, recursos financeiros para desenvolver. Ele se socorria no IPPUC [Instituto de Pesquisa e Planejamento Urbano de Curitiba]". O IPPUC, criado na década de 1960, é conhecido por sua atuação de destaque no planejamento urbano da cidade. 
Ainda assim, a gestão do prefeito Jaime Lerner se destaca no passado do turismo de Curitiba. Isso se deve à sua relação próxima com o IPPUC e a consequente criação de diversos equipamentos de lazer na cidade que se transformaram em atrativos turísticos. Para o entrevistado N14 (setor privado), ainda que ele "não tenha institucionalizado o turismo como entidade, ele prestou um grande serviço porque ele equipou a cidade, criou a base para que o turismo florescesse em Curitiba".

Na década de 1990, na gestão do prefeito Rafael Greca, foi criada a Secretaria de Indústria, Comércio e Turismo, que funcionou até o ano 2000. Os recursos destinados à área do turismo, porém, continuavam escassos (ZARUCH, 2014). Dentre as ações relevantes naquele período, pode-se destacar a participação de Curitiba em workshops na América do Sul (Buenos Aires, Córdoba, Rosário, Montevidéu, Punta del Leste, Assunção e Santiago do Chile). A cidade também participou de feiras em parceria com o governo do estado do Paraná e com a cidade de Foz do Iguaçu. Pela primeira vez, em 1993 Curitiba esteve presente na Feira das Américas, que ocorreu juntamente com o Congresso Nacional da Associação Brasileira de Agências de Viagens (ABAV) em Foz do Iguaçu. Durante aquela década a cidade foi a outros eventos como o Festival de Turismo de Gramado, a Feira de Turismo de Buenos Aires e a Feira de Turismo de Madri, uma das maiores do mundo.

Além da participação em feiras de turismo, no final da década de 1990 Curitiba - através de uma parceria entre prefeitura e governo do estado - captou o Congresso Nacional da ABAV. O evento foi realizado em 1999, no Expotrade (centro de convenções localizado na cidade de Pinhais, na região metropolitana de Curitiba). Cabe observar que Curitiba tinha sido sede de um Congresso da ABAV em 1967, quando o evento tinha proporções significativamente menores, realizando as palestras e a feira no Teatro Guaíra (ZARUCH, 2014).

Durante a década de 1990 foi criado material de divulgação da cidade, inclusive nos idiomas espanhol e inglês. Foram instalados nesse período os primeiros postos de informações turísticas (no antigo bonde do calçadão da Rua XV de Novembro, na praça Tiradentes, na Rua 24 Horas, dentre outros). Nessa época foram criadas ainda a Linha Turismo, passando pelos principais pontos de interesse da cidade; e a Linha Volta ao Mundo, percorrendo os parques 
dedicados às etnias que vieram para Curitiba. As linhas foram posteriormente unificadas (ZARUCH, 2014).

\section{EVOLUÇÃO DA INSTITUCIONALIZAÇÃO PÚBLICA DO TURISMO EM CURITIBA: JUNTOS VENCEREMOS}

De 1993 a 2000, a cidade de Curitiba teve como diretor de turismo o jornalista Júlio Zaruch. Dentre suas ações, destaca-se a comissão de turismo criada no Conselho de Indústria e Comércio, permitindo uma interação mais frequente e organizada entre os empresários e os representantes do setor público na área. Com exceção das organizações empresariais que surgiram a partir dos anos 2000, essa comissão era formada por segmentos empresariais semelhantes aos que atualmente compõem o Conselho Municipal de Turismo.

No segundo mandato do prefeito Cássio Taniguchi (2001-2004), foi extinta a Secretaria de Indústria, Comércio e Turismo, e o turismo se tornou atribuição da Companhia de Desenvolvimento de Curitiba. Nesta havia uma diretoria de turismo voltada para o planejamento, promoção e atendimento, sob chefia do administrador Antônio João Monteiro de Azevedo. Antônio de Azevedo veio a ser eleito presidente nacional da Associação Brasileira de Agências de Viagens (ABAV) em 2011. Segundo Massukado e Teixeira (2007), os empresários entendiam como um problema na relação do setor público com o turismo a inexistência de um órgão independente responsável pelo turismo.

Neste período também houve baixo volume de recursos destinados ao turismo, em grande parte devido às dificuldades de convênios com o estado e com o governo federal. Como exposto por Massukado e Teixeira (2007), isto se deveu à falta de entendimento entre estado e município. Já em relação ao governo federal, o entrave não era político, mas relacionado à forma jurídica do órgão responsável pelo turismo. A então "Diretoria de Turismo [era] parte de uma companhia de economia mista [Companhia de Desenvolvimento de Curitiba - $\mathrm{CIC}$ ] e, portanto, esta[va] impedida de receber recursos federais" (MASSUKADO; TEIXEIRA, 2007:261). As autoras relatam, por exemplo, um projeto de sinalização turística elaborado à época e que não foi executado por falta de recursos financeiros. 
Apesar da histórica carência de recursos para o órgão responsável pela atividade, a ação do setor público em outras frentes fez com que a cidade fosse crescentemente equipada com atrativos turísticos. O setor público municipal também é reconhecido pela formulação e implantação de políticas públicas que garantiram a Curitiba a imagem de cidade com uma boa qualidade de vida. Estas políticas foram implementadas com foco nos moradores locais, mas também favorecem o turismo e, consequentemente, os empresários da área. Isto é salientado por um dos agentes públicos entrevistados:

Curitiba era uma cidade que não era vista como turística (...) os atrativos que fazem parte da Linha Turismo, são atrativos criados pelas mãos do poder público na sua grande maioria (...) as atrações foram criadas para os habitantes, mas se transformaram em atrativos. (...) Curitiba é conhecida pela qualidade de vida, pela forma como ela bem trabalha seus problemas urbanos e foi isso que acabou atraindo as pessoas a virem para Curitiba. (...) Hoje talvez isso não seja tão constante como foi um tempo atrás porque hoje nós temos barreiras burocráticas, barreiras legais e um controle muito mais forte no sentido de implantação de novos atrativos, equipamentos. (ENTREVISTADO Z18 - SETOR PÚBLICO).

Assim, de acordo com Massukado e Teixeira (2007), neste período quase $90 \%$ dos atrativos turísticos pertenciam à prefeitura municipal. Vê-se então que, por um lado, o passado é marcado por uma contribuição positiva na construção de atrativos, o que atualmente se tornou mais difícil. Por outro lado, vê-se também marcas da baixa dotação orçamentária do turismo e a alternância em sua institucionalização no poder público, dificultando o diálogo transparente e sistemático deste com os empresários do ramo.

\section{SALIÊNCIA DA INSTITUCIONALIZAÇÃO PÚBLICA DO TURISMO EM CURITIBA: INSTITUCIONALIZADOS VENCEREMOS}

Como visto, a articulação do turismo na esfera do setor público em Curitiba foi responsabilidade adjacente de diversos órgãos com outro foco de atuação, até que em 2005 foi criado o Instituto Municipal de Turismo (IMT). Isso se deu aproximadamente dois anos após o mesmo ter ocorrido na esfera federal, com a origem de um ministério exclusivo para o turismo. O IMT foi estabelecido como autarquia municipal criada pela Lei Municipal $n^{\circ} 11.408$, de 2005, com a missão de promover o turismo sustentável no município (CURITIBA, 2013). 
Além do IMT, foi criado também o Conselho Municipal de Turismo (COMTUR), através da Lei $n^{\circ}$ 11.835/2006 (CURITIBA, 2013a) e regulamentado pelo Decreto Municipal $n^{\circ}$ 1.597/2009 (CURITIBA, 2014). Como órgão deliberativo, consultivo e de assessoramento, vinculado ao chefe do Poder Executivo, o COMTUR tem como objetivo a conjugação de esforços entre o Poder Público Municipal e a sociedade na aplicação de políticas de incentivo ao turismo. Seus conselheiros permanentes (também chamados de "obrigatórios" no próprio Conselho), num total de 19, vêm das organizações apresentadas no Quadro 1.

\begin{tabular}{|c|c|c|c|c|c|c|}
\hline \multicolumn{3}{|c|}{ CATEGORIA } & \multicolumn{4}{|c|}{ NOMES DAS ORGANIZAÇÕES } \\
\hline \multirow{2}{*}{$\begin{array}{l}\text { SETOR } \\
\text { PÚBLICO }\end{array}$} & \multicolumn{2}{|c|}{$\begin{array}{l}\text { Organizações ligadas } \\
\text { diretamente ao turismo }\end{array}$} & \begin{tabular}{|c|} 
Instituto Municipal de \\
Turismo \\
(representando o chefe \\
do Poder Executivo)
\end{tabular} & $\begin{array}{c}\text { Secretaria de Estado } \\
\text { do Turismo do } \\
\text { Paraná }\end{array}$ & $\begin{array}{l}\text { Fórum } \\
\text { Metropolitano de } \\
\text { Turismo }\end{array}$ & \\
\hline & \multicolumn{2}{|c|}{$\begin{array}{l}\text { Organizações ligadas } \\
\text { indiretamente ao turismo }\end{array}$} & $\begin{array}{l}\text { Câmara Municipal de } \\
\text { Curitiba }\end{array}$ & & & \\
\hline \multirow{7}{*}{$\begin{array}{l}\text { SETOR } \\
\text { PRIVADO }\end{array}$} & \multirow{5}{*}{$\begin{array}{c}\text { Organizações } \\
\text { empresariais } \\
\text { ligadas diretamente ao } \\
\text { turismo }\end{array}$} & $\begin{array}{l}\text { Meios de } \\
\text { Hospedagem }\end{array}$ & $\begin{array}{c}\text { Associação Brasileira da } \\
\text { Indústria de Hotéis } \\
\text { (ABIH) }\end{array}$ & $\begin{array}{c}\text { Associação de } \\
\text { Hostels do Estado do } \\
\text { Paraná }\end{array}$ & & \\
\hline & & $\begin{array}{l}\text { Agenciamento e } \\
\text { Transportes }\end{array}$ & $\begin{array}{c}\text { Associação Brasileira } \\
\text { das Agências de } \\
\text { Viagens do Paraná } \\
\text { (ABAV-PR) }\end{array}$ & & & \\
\hline & & Eventos & $\begin{array}{c}\text { Associação Brasileira de } \\
\text { Centros de Convenções } \\
\text { e Feiras } \\
\text { (ABRACCEF) }\end{array}$ & $\begin{array}{c}\text { Associação Brasileira } \\
\text { de Empresas de } \\
\text { Eventos } \\
\text { (ABEOC) }\end{array}$ & & \\
\hline & & $\begin{array}{l}\text { Alimentos e } \\
\text { Bebidas }\end{array}$ & $\begin{array}{c}\text { Associação Brasileira de } \\
\text { Bares e Restaurantes } \\
\text { (ABRASEL) }\end{array}$ & & & \\
\hline & & Multi-segmetos & $\begin{array}{c}\text { Curitiba Região e Litoral } \\
\text { Convention \& Visitors } \\
\text { Bureau } \\
\text { (CCVB) }\end{array}$ & $\begin{array}{l}\text { Sindicato de Hotéis, } \\
\text { Restaurantes, Bares } \\
\text { e Similares de } \\
\text { Curitiba (SINDOTEL) }\end{array}$ & \begin{tabular}{|c|} 
Sindicato das \\
Empresas de \\
Turismo no Estado \\
do Paraná \\
(SINDETUR) \\
\end{tabular} & \\
\hline & \multicolumn{2}{|c|}{$\begin{array}{l}\text { Organizações empresariais } \\
\text { ligadas indiretamente ao turismo }\end{array}$} & $\begin{array}{c}\text { Associação Comercial } \\
\text { do Paraná (ACP) }\end{array}$ & $\begin{array}{l}\text { Federação do } \\
\text { Comércio do Paraná } \\
\text { (Fecomércio) }\end{array}$ & & \\
\hline & \multicolumn{2}{|c|}{$\begin{array}{l}\text { Organizações profissionais } \\
\text { ligadas ao turismo }\end{array}$} & $\begin{array}{c}\text { Sindicato Estadual dos } \\
\text { Guias de Turismo do } \\
\text { Paraná } \\
\text { (SINDEGTUR) }\end{array}$ & $\begin{array}{c}\text { Associação Brasileira } \\
\text { dos Guias de Turismo } \\
\text { (ABGTUR) }\end{array}$ & \begin{tabular}{|c|} 
Fórum de \\
Coordenadores \\
dos Cursos \\
Superiores de Tur. \\
e Hotelaria do \\
Paraná
\end{tabular} & $\begin{array}{c}\text { Associação } \\
\text { Brasileira de } \\
\text { Jornalistas de } \\
\text { Turismo } \\
\text { (ABRAJET) }\end{array}$ \\
\hline
\end{tabular}

QUADRO 1 - CONSELHEIROS PERMANENTES DO COMTUR

Elaborado pelos autores.

Vê-se ali que há um conjunto diverso de representações. Do setor público são contemplados os poderes executivo e legislativo local, o poder executivo estadual e um fórum que congrega agentes de 26 municípios da região metropolitana de Curitiba. E do setor privado, há diversas associações empresariais e algumas profissionais. 
A trajetória da interação entre empresários e setor público nas políticas públicas de turismo em Curitiba tem como marco a criação do Instituto Municipal de Turismo e do Conselho Municipal de Turismo:

Antes do Instituto Municipal de Turismo a relação era próxima mas era desorganizada, hoje ela é mais organizada. Antes do Instituto Municipal de Turismo não tinha Conselho Municipal de Turismo, antes não tinha uma relação direta do diretor de turismo com o prefeito. Hoje você tem, porque o presidente do Instituto tem um cargo equivalente ao de um secretário. (ENTREVISTADO A8 - SETOR PRIVADO).

Portanto, a partir do IMT e do COMTUR, os empresários passaram a participar de uma instituição exclusiva do turismo, em igualdade de condições para dialogar com os demais órgãos do setor público e com o prefeito. Os empresários também passaram a contar com um fórum institucionalizado exclusivo para debater o turismo na cidade e as ações do setor público relacionadas à atividade.

A interação do setor público com determinados agentes do setor privado é ampliada pelo Decreto Municipal $n^{\circ} 1.597 / 2009$. Além de aprovar o regulamento do COMTUR, ele estabelece ainda vagas para vinte conselheiros rotativos, indicados pelo IMT, como apresentado no Quadro 2. Ali estão listadas as originalmente contempladas na Lei de criação e, marcadas com asterisco, as que foram adicionadas na $12^{a}$ reunião ordinária do COMTUR, realizada em outubro de 2014 (CURITIBA, 2015f).

\begin{tabular}{|c|c|c|c|c|c|c|c|c|c|}
\hline \multicolumn{3}{|c|}{ CATEGORIA } & \multicolumn{7}{|c|}{ NOMES DAS ORGANIZAÇÕES } \\
\hline \multirow{3}{*}{$\begin{array}{l}\text { SETOR } \\
\text { PÚBLICO }\end{array}$} & \multirow{3}{*}{$\begin{array}{c}\text { Organizações } \\
\text { ligadas } \\
\text { indiretamente } \\
\text { ao turismo }\end{array}$} & Municipal & \begin{tabular}{|c|} 
Instituto de \\
Pesquisa e \\
Planejamento \\
Urbano de Curitiba \\
(IPPUC)
\end{tabular} & $\begin{array}{l}\text { Secretaria } \\
\text { Municipal } \\
\text { do Meio } \\
\text { Ambiente }\end{array}$ & $\begin{array}{l}\text { Fundação } \\
\text { Cultural de } \\
\text { Curitiba }\end{array}$ & $\begin{array}{l}\text { Urbanização } \\
\text { de Curitiba } \\
\text { S/A (URBS) }\end{array}$ & $\begin{array}{c}\text { Secretaria } \\
\text { Municipal } \\
\text { de Assuntos } \\
\text { Metropolitanos }\end{array}$ & \begin{tabular}{|c|} 
Agência \\
Curitiba de \\
Desenvolvime \\
nto S/A
\end{tabular} & \\
\hline & & Estadual & $\begin{array}{c}\text { Assembleia } \\
\text { Legislativa do } \\
\text { Estado do Paraná }\end{array}$ & & & & & & \\
\hline & & Federal & $\begin{array}{l}\text { Câmara dos } \\
\text { Deputados }\end{array}$ & $\begin{array}{c}\text { Empresa } \\
\text { Brasileira de } \\
\text { Infraestrutura } \\
\text { Aeroportuária } \\
\text { (INFRAERO) }\end{array}$ & $\begin{array}{l}\text { Universidade } \\
\text { Federal do } \\
\text { Paraná } \\
\text { (UFPR) }\end{array}$ & & & & \\
\hline \multirow{4}{*}{$\begin{array}{l}\text { SETOR } \\
\text { PRIVADO }\end{array}$} & \multirow{3}{*}{$\begin{array}{c}\text { Organizações } \\
\text { empresariais } \\
\text { ligadas } \\
\text { diretamente ao } \\
\text { turismo }\end{array}$} & $\begin{array}{l}\text { Meios de } \\
\text { Hospedagem }\end{array}$ & \begin{tabular}{|c|} 
Fórum de \\
Operadores \\
Hoteleiros do Brasil \\
(FOHB)
\end{tabular} & & & & & & \\
\hline & & $\begin{array}{c}\text { Agenciamento e } \\
\text { Transportes }\end{array}$ & $\begin{array}{l}\text { Associação } \\
\text { Brasileira das } \\
\text { Locadoras de } \\
\text { Automóveis } \\
\text { (ABLA) }\end{array}$ & \begin{tabular}{|c|} 
Associação \\
Brasileira das \\
Operadoras de \\
Trens Turisticos \\
Culturais \\
(ABOTTC) \\
\end{tabular} & $\begin{array}{l}\text { Núcleo de } \\
\text { Turismo } \\
\text { Receptivo }\end{array}$ & & & & \\
\hline & & Multi-segmetos & $\begin{array}{c}\text { CNTUR - } \\
\text { FEHGASTROME / } \\
\text { ABRABAR * }\end{array}$ & & & & & & \\
\hline & \multicolumn{2}{|c|}{$\begin{array}{l}\text { Organizações empresariais } \\
\text { ligadas indiretamente ao turismo }\end{array}$} & $\begin{array}{c}\text { Associação dos } \\
\text { Comerciantes da } \\
\text { Região da Praça da } \\
\text { Espanha } \\
\text { (ASCORES) }\end{array}$ & $\begin{array}{c}\text { Rede Empresarial } \\
\text { do Centro } \\
\text { Histórico * }\end{array}$ & $\begin{array}{l}\text { Associação do } \\
\text { Comércio e } \\
\text { Indústria de } \\
\text { Santa } \\
\text { Felicidade * }\end{array}$ & \begin{tabular}{|c|} 
Sistema \\
Federação \\
das Indústrias \\
do Estado do \\
Paraná \\
(FIEP)
\end{tabular} & $\begin{array}{c}\text { Serviço Social } \\
\text { do Comércio } \\
\text { (SESC) }\end{array}$ & \begin{tabular}{|c|} 
Serviço \\
Brasileiro de \\
Apoio às Micro \\
e Pequenas \\
Empresas \\
(SEBRAE)
\end{tabular} & $\begin{array}{c}\text { Serviço } \\
\text { Nacional de } \\
\text { Aprendizagem } \\
\text { Comercial } \\
\text { (SENAC) }\end{array}$ \\
\hline
\end{tabular}


*Organizações incluídas por meio de decisão tomada na $12^{a}$ reunião ordinária do COMTUR realizada em 4 de outubro de 2014 (CURITIBA, 2015f).

QUADRO 2 - CONSELHEIROS ROTATIVOS DO COMTUR

Elaborado pelos autores

Vê-seumaumentodadiversidadederepresentadosnoCOMTUR, principalmente através da inclusão de organizações públicas e privadas indiretamente ligadas ao turismo. Isso talvez se deva justamente à transversalidade das ações ligadas ao turismo, envolvendo por exemplo obras, eventos culturais, logística, comércio e pesquisa. Já dentre as organizações empresariais diretamente ligadas ao turismo, houve ampliação do número de representantes dos segmentos de agenciamento, transportes e meios de hospedagem.

Também fica evidente que predominantemente as associações facilitam o diálogo com o setor público. Nessa interação as associações levam demandas dos empresários e trazem informações do setor público para os mesmos. Conforme relatado pelo entrevistado F9 (setor privado), "as empresas interagem com associações e elas com o setor público defendendo os interesses dos associados junto aos diferentes órgãos".

Segundo o Decreto, os membros do conselho devem se reunir bimestralmente (CURITIBA, 2014). Ele determina também que sejam lavradas as atas de todas as reuniões, que devem ser lidas, discutidas, aprovadas e assinadas na reunião seguinte, e então arquivadas. Também é proposto que, para um melhor resultado dos trabalhos, no Conselho sejam organizadas Comissões Temáticas. Essas Comissões podem ter em sua composição participantes externos às instituições definidas pelo Decreto, desde que aprovados por unanimidade. Cabe ainda ao Poder Executivo, segundo o Decreto, propiciar o apoio técnico-administrativo e a infraestrutura necessários à operacionalização do Conselho.

Ao longo de sua primeira década de existência o IMT de Curitiba teve quatro presidentes. O primeiro a assumir foi Luiz Carlos de Carvalho, formado em economia, empresário da área de consultoria fiscal e tributária, e membro da SKAL, uma associação internacional de profissionais de turismo (TERRA, 2015). De acordo com o entrevistado Y23, "logo depois ele [Luiz Carlos de Carvalho] foi designado para a Secretaria da Copa e a Juliana Vosnika assumiu. Ela continuou esse trabalho que foi começado pelo Luiz de Carvalho de uma forma intensa". 
Assim, em 2009, assumiu a presidência do IMT Juliana Vosnika, formada em Economia pela Universidade Federal do Paraná e com experiência na diretoria do CCVB. Ela esteve à frente do órgão até 2012, quando começou a gestão do prefeito Gustavo Fruet. Após seis meses de mandato, em junho de 2013, o prefeito nomeou o primeiro presidente do IMT de sua gestão (CURITIBA, 2015), o engenheiro florestal atuante na área de eventos e com experiência na diretoria do CCVB, Paulo Roberto Colnaghi Ribeiro (CURITIBA, 2015a). Este deixou o órgão após pouco mais de um ano. O IMT passou então a ser presidido por Carlos Henrique Sá de Ferrante, historiador com experiência em cargos de gestão do executivo e como vereador de Curitiba (CURITIBA, 2015b).

Dentre as ações mais expressivas do IMT nos seus cinco primeiros anos estão: a realização da $8^{a}$ Conferência das Partes da Convenção sobre Diversidade Biológica e a $3^{a}$ Reunião das Partes do Protocolo de Cartagena sobre Biossegurança (COP-8 e MOP-3), em 2006; a revitalização da Feira de Artesanato do Largo da Ordem (após sua criação o IMT assumiu as feiras de artesanato, antes sob responsabilidade da Fundação Cultural de Curitiba); o desenvolvimento do Fórum Metropolitano de Turismo, em consonância com o Programa de Regionalização, do Ministério do Turismo; a criação do guia turístico Curta Curitiba; e a implantação de postos de informação turística.

Nos cinco anos seguintes de existência do IMT se destacam as ações provenientes de convênios com o Ministério do Turismo, a Galeria de Luz no Natal (instalação ao longo da rua XV de Novembro de um portal e arcos iluminados), e a instalação do posto de informação turística na Rua 24 Horas após sua revitalização.

Em 2012 foi promulgada a Lei Municipal $n^{\circ}$ 14.115/2012, que trata da política pública de turismo local, enfatizando a parceria entre os setores público e privado e também a articulação dos atores locais (CURITIBA, 2013b). Na referida lei também consta que as políticas públicas de turismo devem definir diretrizes que promovam o desenvolvimento da atividade de modo a gerar mais benefícios para as populações locais e minimizar os impactos negativos. A Lei defende o posicionamento de Curitiba como um destino indutor do turismo regional, pela aproximação entre o setor público e o privado, e a 
ISSN: 1983-7151

criação de uma política municipal específica trazendo uma diretriz para desenvolver a atividade minimizando esforços isolados, garantindo a gestão sustentável do turismo em Curitiba.

Dentre as ações do IMT neste período também se encontram o Plano de Desenvolvimento Integrado do Turismo Sustentável (PDITS), a Copa do Mundo de Futebol 2014 e a revitalização da Praça da Espanha. Estas ações foram executadas no mandato do prefeito Gustavo Fruet, embora planejadas nas gestões anteriores.

A elaboração do PDITS de Curitiba é resultado de um convênio entre o IMT e o Ministério do Turismo celebrado em 2010. Seu valor global foi de R $\$ 250$ mil (aproximadamente US\$ 142 mil com o dólar médio de 2010 a R\$1,75). Deste total, $92 \%$ vieram do governo federal e os demais $8 \%$ vieram da contrapartida da Prefeitura Municipal de Curitiba (BRASIL, 2015).

O PDITS é composto por um diagnóstico da cidade com foco no turismo (mercado turístico, infraestrutura básica e serviços gerais, quadro institucional e aspectos socioambientais), validação da mesma como destino turístico, estratégias de desenvolvimento, plano de ação e mecanismos de avaliação (CURITIBA, 2014b). Ele está atrelado aos Programas Regionais de Desenvolvimento do Turismo (PRODETUR), voltados para investimentos em recuperação de atrativos turísticos públicos, acessibilidade, preservação dos recursos naturais e culturais, fortalecimento da imagem dos destinos turísticos e dos órgãos públicos de turismo (BRASIL, 2014c). Assim, caso a prefeitura em algum momento tenha interesse em contratar a linha de crédito do PRODETUR em uma destas áreas, um pré-requisito é que ela tenha elaborado o PDITS.

Em relação à Copa do Mundo de Futebol 2014, o IMT atuou principalmente em projetos de infraestrutura para o turismo. Estes foram provenientes de convênios com o Ministério do Turismo e envolviam três principais frentes. Uma delas era a sinalização turística bilíngue por diversos pontos da cidade. Outras eram ações relacionadas à acessibilidade, envolvendo a infraestrutura no entorno dos atrativos da Linha Turismo e do Zoológico (vide detalhes em BRASIL 2015 a,b,c,d). E outra foi a construção da Central de Atendimento ao Turista do Jardim Botânico, cujo projeto foi elaborado pelo IPPUC (BRASIL, 
2015e). No total, os convênios envolvidos totalizaram quase $R \$ 8,5$ milhões (US\$ 4,8 milhões ao dólar médio de 2010). O Ministério do Turismo arcou com aproximadamente $92 \%$ destes valores, tendo sido o restante a contrapartida da Prefeitura Municipal de Curitiba através do IMT.

Compõem ainda as ações do IMT nos cinco últimos anos de sua primeira década de existência o projeto Coleção de Roteiros Turísticos de Curitiba. Este também é fruto de convênio do IMT com o Ministério do Turismo (BRASIL, 2015f), cobrindo a impressão de mapas trilíngues e de mídia nacional referentes aos roteiros. O rateio dos custos seguiu a proporção fixada nos convênios já mencionados.

Do mesmo período é a revitalização da Praça da Espanha. Ela também foi objeto de convênio do Ministério do Turismo com a Prefeitura Municipal de Curitiba, seguindo as proporções já conhecidas de rateio dos custos (BRASIL, 2015g). A justificativa apresentada no projeto foi a seguinte:

A Praça Espanha está inserida como um dos pontos principais de interesse turístico nas programações de famtour efampress, realizados pelas entidades representativas do Turismo na cidade. Membros do Conselho Municipal de Turismo, a ASCORES contribui para as ações de desenvolvimento e divulgação da atividade turística de Curitiba. A revitalização da acessibilidade da Praça Espanha contribuirá para o fortalecimento da região como produto turístico. (BRASIL, 2015).

A reforma teve a colaboração da Secretaria Municipal do Meio Ambiente e da Fundação Cultural de Curitiba. Assim, as ações dos últimos anos evidenciam a necessidade de interação do IMT com os demais órgãos da prefeitura:

Então qualquer interferência do turismo a gente depende de uma negociação com eles. Essa negociação ainda não é fácil mas (...) as pessoas já passam a compreender melhor. Hoje nas revisões do Plano Diretor eles já chamam o turismo, coisa que não acontecia. Então o turismo está sendo um pouco mais lembrado e inserido nesse planejamento urbano. (ENTREVISTADO R3 - SETOR PÚBLICO).

Portando, há um histórico de esforço do mesmo para se tornar mais próximo deles e sensibilizá-los para o turismo. Como resultado, esta interação entre burocratas se intensificou, levando o turismo a ser mais respeitado e, 
consequentemente, mais inserido na formulação de políticas públicas de outras áreas, mas que afetam o tema.

Dessa forma, os casos listados são representativos da história do IMT. A menção de alguns de seus respectivos valores também serve de parâmetro para expressar a importância do turismo dentro setor público municipal. No total, foram investidos $R \$ 12,3$ milhões (aproximadamente US\$ 7 milhões no dólar médio de 2010) em projetos relacionados ao turismo. Deste montante, cerca de $92 \%$ ( $R \$ 11,3$ milhões) tem como origem o governo federal e $8 \%$ ( $R \$$ 991 mil) a Prefeitura Municipal de Curitiba.

Note-se que orçamento de 2015 da Prefeitura de Curitiba é de aproximadamente R\$7,3 bilhões (US\$2,5 bilhões com o dólar médio de 2015 até maio a $R \$ 2,94$ ). Destes, apenas $R \$ 5,3$ milhões (US\$ 1,8 milhões ao dólar médio de 2015 até maio) são destinados ao IMT, e quase metade deste valor se refere à folha de pagamento (as menções que apresentam o orçamento do IMT para 2015 em aproximados $R \$ 47$ milhões incluem os recursos provenientes de transferências de convênios com o governo federal) (CURITIBA, 2015e).

Há ainda duas iniciativas mais recentes do IMT a se mencionar. Uma é a elaboração do novo site oficial de turismo de Curitiba (o anterior tinha aproximadamente 15 anos). Para tanto foi contratado o Instituto Curitiba de Informática para o desenvolvimento e implantação de software aplicativo, serviços de data center, hospedagem de dados e aplicações, e fotos virtuais para a nova página (CURITIBA, 2015d). Outra foi a implementação do posto de informação turística móvel, utilizando três carros elétricos cedidos ao IMT como parte de uma parceria com a Itaipu Binacional, a Aliança Renault-Nissan e o Centro para a Excelência e Inovação na Indústria do Automóvel (CURITIBA, 2014d).

Além destas ações, houve também a organização das feiras de artesanato, a participação em feiras de turismo, a realização de pesquisa de demanda do turismo em Curitiba, a capacitação turística e o apoio a eventos locais. O apoio a estes últimos foi feito de forma institucional, com disponibilização de palco, iluminação, equipamentos de som e de imagem, licitados pelo IMT.

Em 2015 foi elaborado o Plano Municipal de Turismo de Curitiba 2015 - 2017, em grande parte fruto do esforço de servidores públicos do IMT em elaborá-lo, 
pautando-se num processo participativo tanto da sociedade por meio digital quanto dos membros do Conselho. O plano também se pautou, dentre outros, no Plano de Desenvolvimento Integrado do Turismo Sustentável (PDITS) CURITIBA e no Plano Plurianual (PPA) 2014-2017. A partir dessas fontes foram estabelecidas as áreas estratégicas para a condução da atividade turística na cidade de Curitiba: gestão do turismo; gestão de eventos geradores de fluxo turístico; qualificação dos produtos e serviços turísticos; promoção e comercialização do destino Curitiba; gestão da informação; produção associada ao turismo; Curitiba como destino indutor regional e estadual (CURITIBA, 2015g).

Um projeto de grande visibilidade vinculado ao IMT nesse período é o de construção do Centro de Convenções e Feiras de Curitiba. Este projeto é também resultado de um convênio entre o IMT e o Ministério do Turismo (BRASIL, 2015h), apoiado pela Associação Brasileira de Centros de Convenções e Feiras (Abraccef). A realização da obra envolve ainda a Secretaria Municipal de Planejamento e Administração, o IPPUC e a Agência Curitiba de Desenvolvimento (CURITIBA, 2015c). Contudo, há considerável incerteza entre agentes do setor público e da iniciativa privada se este equipamento de fato será construído conforme previsto.

O histórico dos projetos exposto aponta para a capacidade de articulação e aglutinação de forças do IMT com outras esferas do setor público, principalmente federal, e também com os empresários, para assim implementar ações relacionadas ao turismo em Curitiba. Ainda assim, há incerteza com relação a grandes projetos, como o do centro de convenções, que limitam as expectativas sobre o ritmo e a dimensão dos desenvolvimentos futuros.

\section{INSTITUCIONALIZAÇÃO PÚBLICA DO TURISMO EM CURITIBA:}

VENCEREMOS?

Neste breve histórico da institucionalização do turismo no setor público local a partir da década de 1970, viu-se que foram gradualmente enraizados em seu arbítrio a participação em feiras de turismo, a organização de eventos, a confecção de material de divulgação, a oferta da Linha Turismo e a operação de postos de informação turística. Em particular, durante a gestão do prefeito Jaime 
Lerner, houve na cidade uma notável criação de equipamentos de lazer que se converteram em atrativos turísticos. Ações lideradas por outras instâncias do setor público e com outros propósitos centrais trouxeram um impacto positivo na criação de atrativos para a cidade. Ao mesmo tempo, o turismo em si não via se consolidar um arranjo institucional que amalgamasse a interação dos agentes envolvidos na forma de um órgão municipal específico para a atividade e com autonomia e recursos para a ela se dedicar. Ele era assunto adjacente de outras repartições públicas com focos distintos.

A atuação do setor público no turismo em Curitiba é caracterizada por uma origem de baixa institucionalização ou de inter-relações muito fragmentadas, seguida de um período de relativa aglutinação e organização em órgãos variados do poder público municipal. Em meados dos anos 2000, ele se institucionaliza de forma mais coesa no IMT. Esse arranjo ainda aparenta vulnerabilidades, como deixa transparecer sua pequena dotação orçamentária, sua dependência em relação ao governo federal e execução de ações que estão mais próximas da alçada de outras pastas, como obras e apoio a eventos locais.

Apenas em 2005 foi criada essa organização com tais características, tornandose por isso importante para o ambiente institucional em que o turismo funciona em Curitiba, o Instituto Municipal de Turismo. Dentre as principais ações do IMT, desde sua criação, estão a administração da Feira de Artesanato do Largo da Ordem, a realização da Galeria de Luz no período do natal, o desenvolvimento do Fórum Metropolitano de Turismo, o apoio a feiras gastronômicas e a participação na organização da Copa do Mundo de Futebol 2014 - esta em grande parte vinculada a obras em espaços públicos. Também foram observadas outras ações realizadas pelo setor público e vinculadas ao turismo nas áreas de legislação, planejamento turístico, roteirização e capacitação, e criação e manutenção de infraestrutura e equipamentos turísticos.

É necessário observar que a concretização da principal promessa do setor público para o turismo, o futuro centro de convenções, pode ser um importante peso na balança da institucionalização do turismo na cidade. Os empresários locais têm uma percepção muito direcionada para o turismo de negócios e eventos e buscam influenciar o setor público nesse sentido. 
Sobre o futuro da institucionalização e esse hábito de pensamento e ação dos empresários, cabe uma observação a respeito do turismo de lazer. É evidente a presença de ônibus de turismo na cidade, além dos números da Linha Turismo, aproximadamente 657 mil embarques em 2015 (CURITIBA, 2017). Logo, é importante que os agentes do setor público, como representantes do interesse público, pensem além das pressões empresariais e atuem para estimular o turismo de lazer. Esse segmento envolve outros empreendimentos não contemplados por uma ação pública voltada para o turismo de negócios e eventos.

Nesse cenário o Conselho Municipal de Turismo precisa ser fortalecido como espaço que sustenta uma administração deliberativa do Instituto Municipal de Turismo. Na institucionalização do turismo em Curitiba, a criação do COMTUR foi positiva. Contudo, o seu histórico evidencia a necessidade de transformação desse ambiente tradicionalmente de trocas de relatos das ações do setor público e das demandas individuais da iniciativa privada. Cabe ao COMTUR se transformar em um gerador de sabedoria coletiva em questões estratégicas. Esse conhecimento subsidiará a atuação dos agentes públicos do IMT como indutores, articuladores e executores do interesse público relacionado ao turismo.

Esta condição sugere haver ainda a necessidade de empenhar esforços para aprimorar o arranjo institucional presente a serviço do turismo na esfera do poder público municipal e, portanto, sua capacidade de ajudar de forma sistemática a se ter no turismo um elemento consolidado de promoção do desenvolvimento local.

\section{REFERÊNCIAS}

ALENCAR, E. Pesquisa em Turismo. Lavras: UFLA/FAEPE, 2007.

ALMEIDA, M.H.T. Apresentação. In: VEBLEN, T.B. A Teoria da Classe Ociosa: um estudo econômico das instituições. Tradução Olívia Krähenbühl. São Paulo: Abril Cultural, 1983.

ALONSO, A.D.; BRESSAN, A.; O'SHEA, M.; KRAJSIC, V. Perceived Benefits and Challenges to Wine Tourism Involvement: an international perspective. International Journal of Tourism Research, v.17, n.1, p.66-81, 2015. 
AUGIER, M; KREINER, K. Rationality, imagination and intelligence: some boundaries in human decision-making. Industrial \& Corporate Change, v.9, n.4, p.659-81, 2000.

KOWALSKI, R.L. Número de turistas mais que triplica em Curitiba. Bem Paraná. Curitiba, 13 de janeiro de 2016. Disponível em: http://www.bemparana.com.br/ noticia/424254/ numero-de-turistas-mais-que-triplica-em-curitiba.

BONFIM, I. O. B.; BAHL, M. A cidade de Curitiba - PR/Brasil: o turismo e suas imagens simbólicas. Cultur: Revista de Cultura e Turismo, v. 6, p. 72-85, 2012.

BRASIL. Portal dos Convênios Siconv - Convênio 742472/2010. Disponível em: https://www.convenios.gov.br/siconv/ConsultarProposta/ResultadoDaConsultaDe ConvenioSelecionarConvenio.do? sequencialConvenio $=742472 \&$ Usr $=$ guest $\&$ Pwd $=$ guest. Acesso: 12/6/2015.

BRASIL. Portal dos Convênios Siconv - Convênio 764649/2011. Disponível em: https://www.convenios.gov.br/siconv/ConsultarProposta/ResultadoDaConsultaDe ConvenioSelecionarConvenio.do? sequencialConvenio $=764649 \&$ Us $=$ guest $\&$ Pwd $=$ guest. Acesso em: 12/6/2015a.

BRASIL. Portal dos Convênios Siconv - Convênio 786462/2013. Disponível em: https://www.convenios.gov.br/siconv/ConsultarProposta/ResultadoDaConsultaDe ConvenioSelecionarConvenio.do? sequencialConvenio $=786462 \& U s r=$ guest $\&$ Pwd $=$ guest. Acesso em: 12/6/2015b.

BRASIL. Portal dos Convênios Siconv - Convênio 765174/2011. Disponível em: https://www.convenios.gov.br/siconv/ConsultarProposta/ResultadoDaConsultaDe ConvenioSelecionarConvenio.do? sequencialConvenio $=765174 \&$ Usr $=$ guest $\&$ Pwd $=$ guest. Acesso em: 12/6/2015c.

BRASIL. Portal dos Convênios Siconv - Convênio 786463/2013. Disponível em: https://www.convenios.gov.br/siconv/ConsultarProposta/ResultadoDaConsultaDe ConvenioSelecionarConvenio.do? sequencialConvenio $=786463 \&$ Usr $=$ guest $\&$ Pwd $=$ guest . Acesso em: 12/6/2015d.

BRASIL. Portal dos Convênios Siconv - Convênio 769548/2012. Disponível em: https://www.convenios.gov.br/siconv/ConsultarProposta/ResultadoDaConsultaDe ConvenioSelecionarConvenio.do? sequencialConvenio $=769548 \&$ Usr $=$ guest $\&$ Pwd $=$ guest . Acesso em: 12/6/2015e.

BRASIL. Portal dos Convênios Siconv - Convênio 809895/2014. Disponível em: https:// www.convenios.gov.br/siconv/ConsultarProposta/ResultadoDaConsultaDe

ConvenioSelecionarConvenio.do? sequencialConvenio $=809895 \&$ Usr $=$ guest $\&$ Pwd $=$ guest . Acesso em: 12/6/2015f. 
BRASIL. Portal dos Convênios Siconv - Convênio 769550/2012. Disponível em: https://www.convenios.gov.br/siconv/ConsultarProposta/ResultadoDaConsultaDe ConvenioSelecionarConvenio.do? sequencialConvenio $=769550 \&$ Us $r=$ guest $\&$ Pwd $=$ guest. Acesso em: 12/6/2015g.

BRASIL. Portal da Transparência - Convênio 678529 - Disponível em: http://www. portaldatransparencia.gov.br/convenios/DetalhaConvenio.asp?CodConvenio $=678529 \& \mathrm{Ti}$ poConsulta $=0 \& U F=$ pr $\&$ CodMunicipio $=7535 \&$ CodOrgao $=\&$ Pagina $=1 \&$ Periodo $=$. Acesso em: $12 / 6 / 2015 h$.

BRYANT, A.; CHARMAZ, K. Grounded Theory Research: methods and practices. In: BRYANT, A.; CHARMAZ, K. The Sage Handbook of Grounded Theory. London: Sage Publications, 2010.

CIMOLI, M.; DOSI, G.; NELSON, R. R.; STIGLITZ, J. Instituições e Políticas Moldando o Desenvolvimento Industrial: uma nota introdutória. Revista Brasileira de Inovação, v.6, n.1, p.55-85, 2007.

CINTRA, R.F.; AMÂNCIO-VIEIRA, S.F.; COSTA, B.K. Stakeholder Theory e Institucionalismo Sociológico: complementações para análise do turismo de Londrina-PR. Revista Iberoamericana de Turismo, v.6, n. 1, p.165-186, 2016.

COMMONS, J. R. Institutional economics. American Economic Review, v. 21, n.4, p.648657, 1931.

CURITIBA. Lei n. 11.408, de 10 de maio de 2005. Cria o Instituto Municipal de Turismo CURITIBA TURISMO. Disponívelem: http://www.cmc.pr.gov.br/wspl/sistema/BibLegVerForm. do? select_action=\&ordena $=$ Lei\%20ordin\%E1ria\%2011\%20408\%202005\&popup=s\&nor_ id $=12331$. Acesso: $27 / 8 / 2013$.

CURITIBA. Lei n. 11.835, de 6 de julho de 2006. Institui o Conselho Municipal de Turismo COMTUR. Disponível em: http://www.cmc.pr.gov.br/wspl/sistema/biblegverform.do?select_ action=\&popup=s\&chamado_por_link\&nor_id=12758\&pesquisa=turismo.

Acesso: 27/8/2013a.

CURITIBA. Lei n. 14.115, de 17 de outubro de 2012. Dispõe sobre a Política Municipal do Turismo de Curitiba. Disponível em: http://www.cmc.pr.gov.br/wspl/sistema/BibLegVerForm. do? select_action=\&ordena =Lei\%20ordin\%E1ria\%2014\%20115\%202012\&popup=s\&nor_ id $=15270$. Acesso em: 27/8/2013b.

CURITIBA. Decreto $\mathbf{N}^{\circ} \mathbf{1 . 5 9 7}$, de 15 de dezembro de 2009. Aprova o regulamento do Conselho Municipal de Turismo - COMTUR e dá outras providências. Curitiba, PR. Disponível 
ISSN: 1983-7151

em: http://legisladocexterno.curitiba.pr.gov.br/DiarioConsultaExterna_Pesquisa.aspx. Acesso em: 20/11/2014.

CURITIBA. Instituto Municipal de Turismo. Plano de Desenvolvimento Integrado do Turismo Sustentável. Curitiba, 2014b. 1CD-ROM.

CURITIBA. Galeria de Luz estreia com aplausos de 30 mil pessoas. Disponível em: http://www.curitiba.pr.gov.br/noticias/galeria-de-luz-estreia-com-aplausos-de-30-milpessoas/28043. Acesso 18/11/2014c.

CURITIBA. Decreto N 906. Revoga o Decreto Municipal n. ${ }^{\circ}$ 231/2013. Disponível em: http://legisladocexterno.curitiba.pr.gov.br/DiarioConsultaExterna Download. aspx?Id=979. Acesso em: 13/06/2015.

CURITIBA. Presidente: Paulo Roberto Colnaghi Ribeiro. Disponível em: http://www. curitiba.pr.gov.br/conteudo/presidente-imt/34. Acesso em: 14/06/2015a.

CURITIBA. Caíque Ferrante assume presidência do CTur. Disponível em: http://www. curitiba.pr.gov.br/noticias/caique-ferrante-assume-presidencia-do-ctur/33894. Acesso 14/06/2015b.

CURITIBA. Novo Centro de Convenções de Curitiba será construído atrás do Parque da Imigração Japonesa. Disponível em: http://www.curitiba.pr.gov.br/noticias/novocentro-de-convencoes-de-curitiba-sera-construido-atras-do-parque-da-imigracaojaponesa/35122. Acesso em:14/06/2015c.

CURITIBA. Dispensa de Licitação - TCE - 1 / 2014. Disponível em: http://consultalicitacao. curitiba.pr.gov.br:9090/ConsultaLicitacoes/pages/consulta/consultaProcessoDetalhada. jsf\#. Acesso: 14/06/2015d.

CURITIBA. Lei n. 14.585, de 30 de dezembro de 2014. Estima a Receita e fixa a Despesa do município de Curitiba para o exercício financeiro de 2015. Disponível em: http://www. cmc.pr.gov.br/wspl/sistema/BibLegVerForm.do?select action=\&popup =s\&chamado_por_ link\&nor_id=15785\&pesquisa=loa\%202015. Acesso: 16/6/2015e.

CURITIBA. Ata da 12a Reunião Ordinária do Conselho Municipal de Turismo, realizada em 09 de outubro de 2014. Disponível em: http://portaldosconselhos.curitiba.pr.gov.br/ atasdeliberacoes-14/. Acesso: 25/6/2015f.

CURITIBA. Instituto Municipal de Turismo. Plano Municipal de Turismo de Curitiba 2015 - 2017. Curitiba, 2015g. 
CURITIBA. Estatísticas Mensais - Atendimentos nos PITs, Embarques na Linha Turismo e Visitas à Torre Panorâmica 2015. Disponível em: http://multimidia.turismo.curitiba.pr.gov. br/2016/3/pdf/00001050.pdf. Acesso: 12/3/2017.

DOCTOR, M. Institutional Modernisation and the Legacy of Corporatism: the case of Port Reform in Brazil. Journal of Latin American Studies, v. 35, n.2, p. 341-365, 2003.

GOMES, B. M. A. Políticas Públicas e as Transações em Regiões Turísticas. São Paulo: All Print, 2008.

GRECHI, D. C. O desenvolvimento turístico sob a ótica da economia institucional: uma análise do caso de Bonito (MS). Tese (Doutorado em Economia) - Faculdade de Ciências Econômicas, Universidade Federal do Rio Grande do Sul, Porto Alegre, 2011.

HALL, P A.; TAYLOR, R. C. R. As três versões do neoinstitucionalismo. Lua Nova, v. 53, p. 193-223, 2003.

HAMILTON, W.H. The Institutional Approach to Economic Theory. The American Economic Review. Supplement, Papers and Proceedings of the Thirty-First Annual Meeting of the American Economic Association, v. 9, n. 1, p. 309-318, 1919.

HODGSON, G. The hidden persuaders: institutions and individuals in economic theory. Cambridge Journal of Economics, v.27, n.2, p. 159-175, 2003.

HODGSON, G.M. The Revival of Veblenian Institutional Economics. Journal of Economic Issues, v. 41, n. 2, p. 325-340, 2007a.

IMMERGUT, E.M. The Theoretical Core of the New Institutionalism. Politics \& Society, v. 26, n.1, p. 5-34, 1998.

LIGERO, F.J.R. Análisis Institucional de las Prácticas de Gestión Ambiental de los Campos de Golf Andaluces. Tesis Doctoral - Facultad de Ciencias Empresariales, Universidad de Huelva, Huelva, España, 2010.

MASSUKADO, M. S.; TEIXEIRA, R. M. A Visão Baseada em Recursos na Gestão Pública do Turismo: o caso de Curitiba - PR. Turismo em Análise, v.19, n.2, p.255-271, 2008.

MASSUKADO, M.S.N. A Formação do Arranjo da Regionalização do Turismo no Paraná no Período de 2003-2011. 184f. Tese (Doutorado em Administração) - Setor de Ciências Sociais Aplicadas, Universidade Federal do Paraná, Curitiba, 2011.

MENDONÇA, M.C.A. Gestão de Potenciais Clusters Turísticos: uma proposta de metodologia de diagnóstico. In: BENI, M. C. (org.). Turismo: planejamento estratégico e capacidade de gestão. Barueri: Manole, 2012. 
MOURA, R. O Turismo no Projeto de Internacionalização da Imagem de Curitiba. Turismo - Visão e Ação, v.3, n.9, p.341-357, 2007.

PARANÁ (Secretaria de Estado do Esporte e do Turismo. Paraná Turismo). SERVIÇO BRASILEIRO DE APOIO ÀS MICRO E PEQUENAS EMPRESAS (Sebrae-PR). Paraná - Estudo Estatístico 20 Anos de Turismo. Curitiba, 2014.

PESSALI, H. F.; DALTO, F.A.S. A mesoeconomia do desenvolvimento econômico: o papel das instituições. Nova Economia, v.20, n.1, p.11-37, 2010.

PIMENTEL, M.P.C. Uma discussão teórico-metodológica para a análise das políticas públicas de turismo no Brasil. In: PIMENTEL, T.D.; EMMENDOERFER, M.L.TOMAZZONI, E.L. (Org.) Gestão Pública do Turismo no Brasil: teorias metodologias e aplicações. Caxias do Sul: Educs, 2014.

RAWLENCE, S. Integrating Transaction Cost and Institutional Theories in an Emerging Market Context: the case of the Tiger Leaping Gorge, Southwest China. Thesis (PhD). The University of Edinburgh, Edinburgh, Scotland, 2010.

SCOTT, W.R. Institution and Organization: ideas and interests. California: Sage Publications, 2008.

STRAUSS, A.; CORBIN, J. Pesquisa Qualitativa: técnicas e procedimentos para o desenvolvimento de teoria fundamenta. Trad. Luciane de Oliveira da Rocha. Porto Alegre: Artmed, 2008.

TAROZZI, MASSIMILIANO. O que é grounded theory: metodologia de pesquisa e de teoria fundamentada nos dados. Trad. Carmem Lussi. Petrópolis: Vozes, 2011.

THÉRET, B. As instituições entre as estruturas e as ações. Lua Nova, v. 58, p.225-254, 2003.

ZARUCH, L. J. [Entrevista sobre o Histórico do Turismo em Curitiba]. 2014. Não publicado.

\section{CONTRIBUIÇÃO DOS AUTORES NA CONSTRUÇÃO DO ARTIGO}

GOMES: Introdução, Marco Teórico, Metodologia, Coleta de Dados, Resultados e Considerações Finais.

PESSALI: Introdução, Marco Teórico, Resultados e Considerações Finais. 